\title{
Evaluation of acute alterations in electrocardiographic parameters after cryoballoon ablation of atrial fibrillation and possible association with recurrence
}

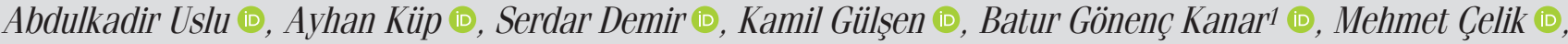 \\ Gökay Taylan² (1D, Alper Kepez ${ }^{\mathbb{D}}$, Taylan Akgün $\mathbb{1}$ \\ Department of Cardiology, Kartal Koşuyolu Heart Training and Research Hospital; İstanbul-Turkey \\ ${ }^{1}$ Department of Cardiology, Faculty of Medicine, Marmara University; İstanbul-Turkey \\ 2Department of Cardiology, Faculty of Medicine, Trakya University; Edirne-Turkey
}

\section{ABSTRACT}

Objective: This study aimed to evaluate the acute effect of cryoballoon ablation (CB-A) on electrocardiographic parameters that have been suggested to reflect heterogeneity in atrial conduction and ventricular repolarization.

Methods: A total of 67 patients (52.6 \pm 13.2 years, 43 men) without any exclusion criteria who had undergone CB-A for atrial fibrillation (AF) between January 01, 2015, and December 31, 2018, constituted our study population. Electrographic recordings obtained before and after the ablation procedure on the same day were retrospectively evaluated for the P-wave dispersion, QTc dispersion, Tp-Te interval, and Tp-Te/0T ratio. The pre- and post-ablation values were tested for significant differences. The association of the possible CB-A-related changes in these parameters with $\mathrm{AF}$ recurrence during follow-up was evaluated.

Results: $P$ dispersion $(30.1 \pm 6.8$ vs. $35.9 \pm 9.4 \mathrm{~ms}, \mathrm{p}<0.001)$, QT dispersion $(20.7 \pm 7.5$ vs. $24.0 \pm 8.8 \mathrm{~ms}, \mathrm{p}<0.001)$, Tp-Te duration (on V5 $83.6 \pm 8.1$ vs. $110.2 \pm 9.5 \mathrm{~ms}, \mathrm{p}<0.001$ ), and Tp-Te/0T ratio (on V $0.22 \pm 0.03$ vs. $0.28 \pm 0.02, \mathrm{p}<0.001$ ) were observed to increase significantly after CB-A. There was no association between the magnitudes of change in any parameter and AF recurrence.

Conclusion: $\mathrm{CB}-\mathrm{A}$ had significant effects on electrocardiographic parameters related to atrial conduction and ventricular repolarization in the acute phase after CB-A. Further prospective studies are required to examine the time-related course of these alterations and their impact on clinical outcomes.

Keywords: atrial fibrillation, catheter ablation, 12-lead electrocardiography

Cite this article as: Uslu A, Küp A, Demir S, Gülşen K, Kanar BG, Çelik M, et al. Evaluation of acute alterations in electrocardiographic parameters after cryoballoon ablation of atrial fibrillation and possible association with recurrence. Anatol J Cardiol 2021; 25: 468-75.

\section{Introduction}

Catheter ablation of symptomatic paroxysmal atrial fibrillation (AF) is recommended to improve symptoms in patients with recurrent symptoms on antiarrhythmic drug therapy (1). Catheter AF ablation may also be considered in patients with symptomatic persistent AF refractory to antiarrhythmic drug therapy; however, ablation has been reported to be less effective in this patient population (1). Catheter ablation of AF may also have a role in patients with symptomatic paroxysmal AF as a first-line therapy to prevent recurrent $A F$ and to improve symptoms in selected patients $(1,2)$. Pulmonary vein isolation (PVI) is the standard and essential procedure for $\mathrm{AF}$ catheter ablation $(1,2)$.
PVI using cryoballoon ablation (CB-A) is a safe and effective alternative to radiofrequency ablation in which point-by-point ablation may be a challenging procedure (3).

$\mathrm{AF}$ is associated with electrical, structural, and autonomic remodeling (4). Shortening of atrial action potentials is a common finding in association with electrical remodeling, and progression of atrial fibrosis is the leading event during structural remodeling (4). Increased density of sympathetic and parasympathetic innervations with AF has been reported in animal studies (5-7). The presence of heterogeneous atrial sympathetic hyperinnervation has also been shown in patients with persistent AF (8). Irreversible structural remodeling may lead to perpetuation of $A F$, and early intervention may have an impact on the progression of the disease (4).

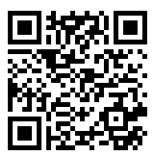

Address for Correspondence: Dr. Alper Kepez, Marmara Üniversitesi Tıp Fakültesi,

Kardiyoloji Anabilim Dalı, İstanbul-Türkiye

Phone: +90 2166254719 E-mail: alperkepez@yahoo.com

Accepted Date: 08.01.2021 Available Online Date: 25.05.2021

(C) Copyright 2021 by Turkish Society of Cardiology - Available online at www.anatoljcardiol.com DOI:10.5152/AnatolJCardiol.2021.33726 


\section{HIGHLIGHTS}

- The authors have evaluated the acute effect of cryoballoon ablation (CB-A) of atrial fibrillation (AF) on electrocardiographic parameters that have been suggested to reflect heterogeneity in atrial conduction and ventricular repolarization.

- $\quad$ CB-A had significant effects on P dispersion, OT dispersion, $\mathrm{Tp}-\mathrm{Te}$ value, and $\mathrm{Tp}-\mathrm{Te} / \mathrm{QT}$ ratio in the acute phase.

- However, there was no association between the magnitudes of change in any parameter and AF recurrence.

Electrocardiographic P-wave dispersion has been assumed to reflect inhomogeneous atrial conduction, and it has been suggested to be a predictor of paroxysmal AF (9). OT dispersion and the Tp-Te interval have been assumed to be noninvasive markers of a state of heterogeneity and transmural dispersion of ventricular repolarization, respectively (10). The $\mathrm{Tp}-\mathrm{Te} / \mathrm{OT}$ ratio is a novel ventricular repolarization parameter that has been suggested to be a valuable predictor of cardiac arrhythmias (10). The $\mathrm{Tp}-\mathrm{Te} / \mathrm{QT}$ ratio includes both transmural dispersion ( $\mathrm{Tp}-\mathrm{Te}$ ) and spatial dispersion (OT) of ventricular repolarization, and it has been suggested to be less vulnerable to the effects of heart rate (10).

CB-A has been associated with intrinsic cardiac autonomic nervous system (ANS) modulation possibly through effect on left atrial (LA) ganglionated plexi (GP) (11). We hypothesized that the acute effect of AF cryoablation on the LA musculature and the cardiac ANS may alter electrocardiographic parameters. This study aimed to evaluate the acute effect of AF cryoablation on electrocardiographic parameters that have been suggested to reflect heterogeneity in atrial conduction and ventricular repolarization. We also aimed to investigate the possible association between alterations in these parameters and recurrence of $\mathrm{AF}$ during follow-up.

\section{Methods}

\section{Patients and study design}

A total of 73 patients ( 45 men, mean age $52.3 \pm 13.0$ years) without any exclusion criteria who had undergone CB-A for AF between January 1, 2015, and December 31, 2018, constituted our study population. CB-A for AF was considered mainly for patients with symptomatic paroxysmal $A F$ who were refractory to antiarrhythmic drug therapy. CB-A was also performed in some patients with symptomatic persistent AF owing to debilitating symptoms that were refractory to medical treatment. Data from a detailed medical history and electrocardiogram (ECG) acquired earlier and after the ablation procedure on the same day were retrospectively obtained from the patient files for each patient. The electrocardiographic parameters that are described in detail in the following section were recorded from the pre- and post- procedure ECGs and compared with each other for all the patients. Post-procedural follow-up data were also obtained retrospectively from recordings of control visits in the arrhythmia polyclinic. Patients were scheduled for outpatient clinic visits in the $1^{\text {st }}, 3^{\text {rd }}, 6^{\text {th }}$, and $12^{\text {th }}$ months and yearly thereafter. Patients were also examined if they experienced symptoms that could be related to AF recurrence. Any documentation of AF episodes lasting $>30 \mathrm{~s}$ with Holter recordings or 12-lead ECG after the CB-A procedure was accepted as recurrence. Recurrence within the 3-month period was termed "early recurrence," and recurrence after 12 months was termed "late recurrence". Any association between the magnitude of change of electrocardiographic parameters and recurrence was investigated.

Patients with atrial fibrillation/flutter, a paced rhythm, and/or complete/incomplete bundle branch block at the time of procedure were excluded from the study. Other exclusion criteria were a history of hypertrophic cardiomyopathy and/or severe valvular heart disease. Patients who had significant procedurerelated complications (tamponade, systemic embolization, and hemodynamic instability) that necessitated interruption of the procedure were also excluded. The Local Ethics Committee approved the study protocol.

\section{Cryoballoon ablation procedure}

All the procedures were performed with uninterrupted oral anticoagulation with warfarin if the international normalized ratio (INR) was <2.5. A novel oral anticoagulant (NOAC) dose was skipped on the day of the procedure. Antiarrhythmic drugs were discontinued 5 days prior to the procedure. All patients underwent transesophageal echocardiography the day before the procedure to exclude the presence of a thrombus in the LA or left atrial appendage (LAA).

All the procedures were performed under conscious sedation by the administration of midazolam and fentanyl boluses. LA access was obtained through a single transseptal puncture with a steerable 12-F sheath (FlexCath Advance, Medtronic, Minneapolis, USA). A 28-mm CB (Arctic Front Medtronic, Minneapolis, USA) was advanced into the LA with a mapping catheter (Achieve, Medtronic, Minneapolis, USA) inside its lumen through the FlexCath sheath. The Achieve catheter was placed into the pulmonary veins for monitoring of electrical activity. The CB was advanced towards the ostia of the pulmonary veins and inflated. Freezing was initiated after demonstration of the cessation of flow into the pulmonary vein when selective contrast agent injection showed total contrast retention with no backflow to the atrium. Cryoablation was applied for 240 $\mathrm{ms}$ for each vein if $-40^{\circ} \mathrm{C}$ could be achieved within $60 \mathrm{~s}$, and disappearance of pulmonary vein potentials could be achieved within $90 \mathrm{~s}$. Otherwise, the balloon was deflated and repositioned with the intention of finding an alternative position with optimal occlusion. A second freeze cycle was then delivered for 180 msec. To avoid phrenic nerve palsy (PNP), diaphragmatic stimulation was achieved by pacing the ipsilateral nerve with a 1000-ms cycle and 20-mA output during ablation of right-sided veins. Phrenic capture was monitored by diaphragmatic con- 
tractions on the fluoroscopy screen. In patients with decreased movement of diaphragmatic contraction, freezing was stopped immediately. Successful PVI was achieved when all the PV potentials were abolished or dissociated from atrial activity. Electrical PV isolation was confirmed by entrance and exit block maneuvers by pacing from coronary sinus and Achieve catheters, respectively. Parenteral anticoagulation with heparin was applied with the aim of maintaining an activated clotting time of $>300$ s during the procedure. Following sheath removal, a figureof-eight suture was applied in all patients.

Post-procedurally, the patients were monitored in the ward for 24 hours, and anticoagulation was initiated 4-6 hours after the procedure. Systemic anticoagulation with a vitamin $\mathrm{K}$ antagonist (VKA) or a novel oral anticoagulant (NOAC) was recommended for at least 3 months after the procedure for all the patients. Decisions regarding the continuation of anticoagulation after 3 months were made on the basis of the $\mathrm{CHA}_{2} \mathrm{DS}_{2}$ VASc risk score. Preprocedural antiarrhythmic drugs were continued for 3 months after the procedure.

\section{Electrocardiographic measurements}

All standard 12-lead ECGs were obtained before and at the end of the CB-A for each patient using a recorder (Schiller AT-2 plus, Switzerland) set with a paper speed of $50 \mathrm{~mm} / \mathrm{s}$ and a standardization of $1 \mathrm{mV} / \mathrm{cm}$. These were scanned for online analysis using the CardioCalipers program (Version 3.3 for Windows, Iconico, www.iconico.com). A total of 3 consecutive cycles were measured in each of the standard 12 leads; and the mean of each parameter was calculated from these values and included in the analysis. A total of 20 randomly selected ECGs were reexamined by the same cardiologist and another cardiologist, both of whom were blinded to the classification of the patients during the examination for the calculations of intraobserver and interobserver variability.

The beginning of the $\mathrm{P}$ wave was defined as the point where the initial deflection of the $\mathrm{P}$ wave crossed the isoelectric line, and the end of the $P$ wave was defined as the point where the final deflection of the $P$ wave crossed the isoelectric line. $P$ maximum (Pmax) was defined as the P-wave duration in any lead with the longest interval, and $P$ minimum (Pmin) was defined as the P-wave duration in any lead with the shortest interval. P-wave dispersion was calculated by subtracting Pmin from Pmax. Derivations were excluded if the beginning or the ending of the P-wave could not be clearly identified. Only recordings with more than 8 analyzable leads were included.

The OT interval was measured from the onset of the ORS complex to the end of the T wave. The end of the T wave was defined as the intersection of the tangent to the down slope of the $T$ wave and the isoelectric line when not followed by a $U$ wave or if distinct from the following $U$ wave. If a $U$ wave followed the T wave, the T wave offset was measured as the nadir between the $T$ and $U$ waves. Only recordings with more than 8 analyzable leads were included. OT maximum was determined as the $\mathrm{OT}$ interval in any lead with the longest interval, and $\mathrm{OT}$ minimum was determined as the $\mathrm{OT}$ interval in any lead with the shortest interval. Measured OT intervals were corrected for heart rate with Bazett's formula ( $0 T C=0 T / \sqrt{R R})$. The corrected OTd (OTcd) was defined as the difference between the corrected maximum (OTcmax) and minimum OT (OTcmin) interval among the 12 ECG leads. The Tp-Te interval was measured from $T_{\text {peak }}$ to $T_{\text {end }}$ on leads V4, V5, and V6. T waves with an amplitude less than $1.5 \mathrm{~mm}$ or $\mathrm{T}$ waves with distorted morphology were excluded from analysis. The $\mathrm{Tp}-\mathrm{Te} / \mathrm{OT}$ ratio was calculated separately on leads $\mathrm{V} 4, \mathrm{~V} 5$, and $\mathrm{V} 6$.

\section{Statistical analysis}

All statistical tests were performed with a commercially available statistical analysis program (SPSS 16.0 for windows, SPSS Inc., Chicago, Illinois, United States). The distribution of the data was tested using a one-sample Kolmogorov-Smirnov test. Values displaying a normal distribution were expressed as the mean \pm standard deviation, and values not displaying a normal distribution were expressed as medians with interquartile ranges. Categorical variables were expressed in ratios. Significant differences in the electrocardiographic parameters obtained before and after the CB-A procedure were tested with paired Student's t-tests for parametric measures and with the Wilcoxon signed-rank test for nonparametric measures. Differences in continuous variables between 2 independent groups were tested by Student t-tests once normality was demonstrated. Otherwise, a nonparametric test (Mann-Whitney $U$ test) was used. Differences in categorical variables between 2 independent groups were tested with the chi-squared test. Correlations between the variables were assessed with the

\begin{tabular}{|c|c|}
\hline Age (years) & $52.6 \pm 13.2$ \\
\hline Sex (Female, \%) & $24(35.8 \%)$ \\
\hline Hypertension (n, \%) & $24(32.9 \%)$ \\
\hline Diabetes mellitus ( $\mathrm{n}, \%$ ) & $9(13.4 \%)$ \\
\hline BMI $\left(\mathrm{kg} / \mathrm{m}^{2}\right)$ & $26.6 \pm 2.6$ \\
\hline Obesity (BMI $\geq 30 \mathrm{~kg} / \mathrm{m}^{2}$ ) & $12(17.9 \%)$ \\
\hline Anemia (n, \%) & $7(10.4 \%)$ \\
\hline Coronary artery disease $(n, \%)$ & $5(7.5 \%)$ \\
\hline Chronic renal failure (n, \%) & $5(7.5 \%)$ \\
\hline Ejection fraction (\%) & $60.4 \pm 6.7$ \\
\hline Left ventricle end-diastolic diameter (mm) & $46.6 \pm 2.7$ \\
\hline Left atrial diameter (mm) & $37.7 \pm 4.2$ \\
\hline Left ventricular hypertrophy (n, \%) & $4(6 \%)$ \\
\hline $\begin{array}{l}\text { Left ventricular systolic dysfunction }(E F<50 \%) \\
(n, \%)\end{array}$ & $5(7.5 \%)$ \\
\hline $\begin{array}{l}\text { Time elapsed since AF diagnosis (months), } \\
\text { median (IQR) }\end{array}$ & $28(18)$ \\
\hline $\mathrm{CHA}_{2} \mathrm{DS}_{2}$-VASc score, median (IOR) & $1(2)$ \\
\hline
\end{tabular}




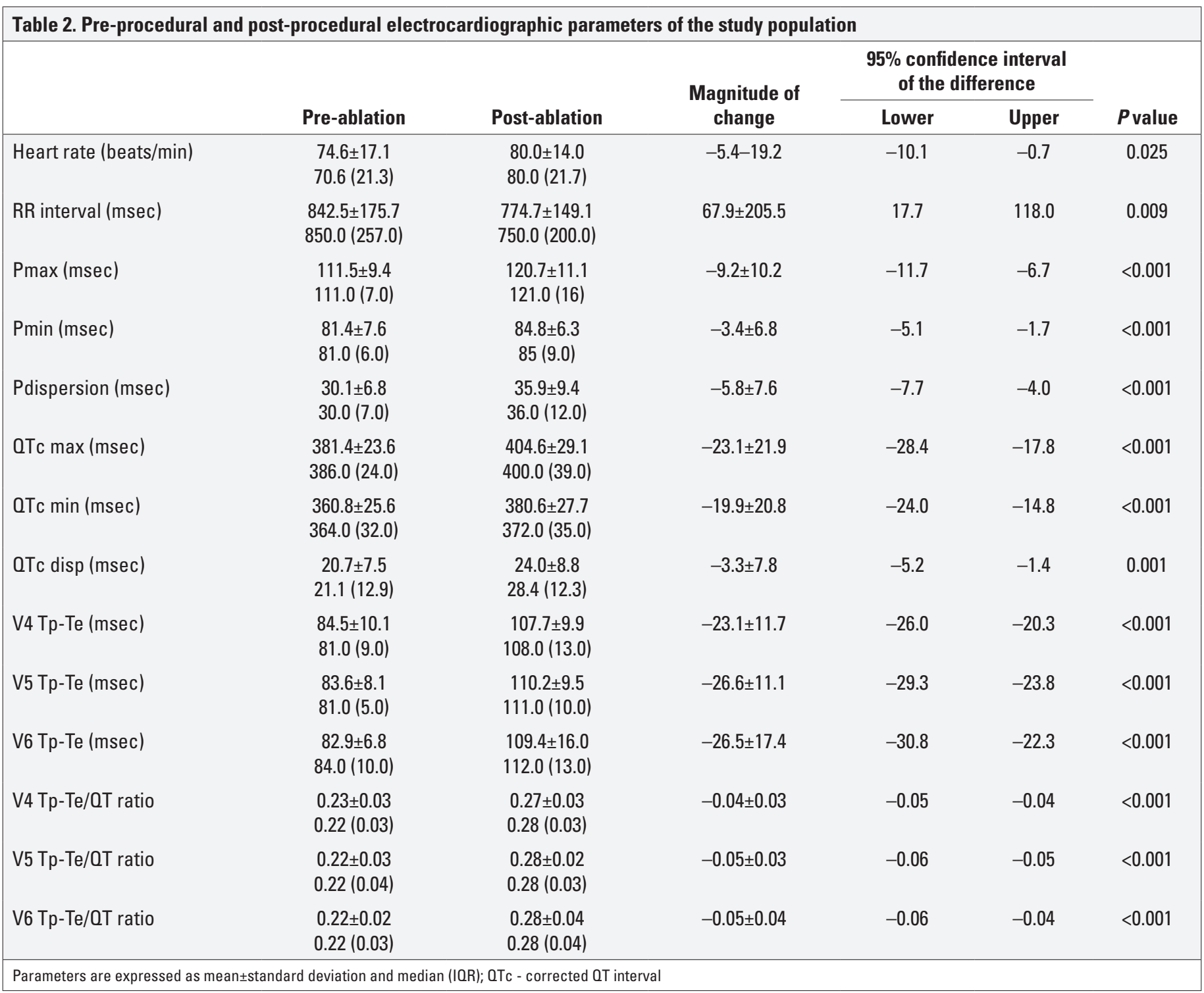

Pearson or Spearman rank correlation test where appropriate. Binary logistic regression analysis was performed to investigate the parameters that might serve as independent predictors of recurrence of AF. Parameters that were observed to change significantly after CB-A were included in the model. Odds ratio and $95 \%$ confidence interval for odds ratio were computed for each variable that was included in the model. A significance level was set at $p<0.05$.

\section{Results}

The study population consisted of 73 patients ( 45 men, mean age $52.3 \pm 13.0$ years); 3 patients were lost to follow-up, and complete PVI could not be achieved in 3 patients. None of the patients had significant complications such as tamponade or systemic embolization that necessitated interruption of the procedure. After excluding these 6 patients, the data of the remaining 67 patients (43 men, mean age $52.6 \pm 13.2$ years) were used in the analysis. The demographic characteristics, cardiovascular risk profiles, and echocardiographic parameters of the patient population are displayed in Table 1. Of the patients, $60(89.6 \%)$ were followed with a diagnosis of paroxysmal $A F$, and the remaining $7(10.4 \%)$ were followed with a diagnosis of persistent $\mathrm{AF}$ at the time of CB-A. The chief complaint of the patient population was palpitations in 63 patients $(94.0 \%)$ followed by exertional dyspnea in 2 patients $(3.0 \%), 1$ patient $(1.5 \%)$ displayed presyncopal symptoms during AF episodes. A total of 22 patients $(32.8 \%)$ were on beta-blockers, $4(6.0 \%)$ were on calcium channel blockers, and $16(23.9 \%)$ were on propafenone for the prevention of AF episodes. The remaining 25 patients $(37.3 \%)$ were not receiving any antiarrhythmic medication at the time of the CB-A. All the patients were anticoagulated. A total of 22 patients $(32.8 \%)$ had been using warfarin, and the remaining $45(67.2 \%)$ were using NOACs at the time of the procedure.

The electrocardiographic parameters that were obtained from pre- and post-procedural ECGs are displayed in Table 2. 


\begin{tabular}{|c|c|c|c|}
\hline & $\begin{array}{l}\text { Free of } \\
\text { recurrence } \\
(n=58)\end{array}$ & $\begin{array}{l}\text { AF recurrence } \\
\qquad(n=9)\end{array}$ & $P$ value \\
\hline Age (years) & $52.4 \pm 12.6$ & $53.9 \pm 17.4$ & 0.806 \\
\hline Sex (Female, \%) & $21(36.2 \%)$ & $3(33.3 \%)$ & 0.591 \\
\hline Hypertension (n, \%) & $21(36.2 \%)$ & $1(11.1 \%)$ & 0.132 \\
\hline Diabetes mellitus (n, \%) & $7(12.1 \%)$ & $2(22.2 \%)$ & 0.347 \\
\hline BMI (kg/m²) & $26.7 \pm 2.8$ & $26.7 \pm 2.1$ & 0.988 \\
\hline $\begin{array}{l}\text { Obesity } \\
\left(B M I \geq 30 \mathrm{~kg} / \mathrm{m}^{2}\right)\end{array}$ & $11(19.0 \%)$ & $1(11.1 \%)$ & 0.490 \\
\hline Anemia (n, \%) & $5(8.6 \%)$ & $2(22.2 \%)$ & 0.235 \\
\hline $\begin{array}{l}\text { Coronary artery disease } \\
(n, \%)\end{array}$ & $4(6.9 \%)$ & $1(11.1 \%)$ & 0.526 \\
\hline $\begin{array}{l}\text { Chronic renal failure } \\
(n, \%)\end{array}$ & $3(5.3 \%)$ & $2(22.2 \%)$ & 0.134 \\
\hline Ejection fraction (\%) & $61.2 \pm 6.0$ & $55.6 \pm 8.8$ & 0.017 \\
\hline $\begin{array}{l}\text { Left ventricle end- } \\
\text { diastolic diameter (mm) }\end{array}$ & $46.5 \pm 2.7$ & $47.4 \pm 3.1$ & 0.318 \\
\hline Left atrial diameter (mm) & $37.2 \pm 4.1$ & $40.4 \pm 3.8$ & 0.031 \\
\hline $\begin{array}{l}\text { Left ventricular } \\
\text { hypertrophy }(n, \%)\end{array}$ & $4(7.0 \%)$ & $0(0 \%)$ & 0.554 \\
\hline $\begin{array}{l}\text { Left ventricular systolic } \\
\text { dysfunction }(\mathrm{EF}<50 \%) \\
(\mathrm{n}, \%)\end{array}$ & $3(5.2 \%)$ & $2(22.2 \%)$ & 0.130 \\
\hline $\begin{array}{l}\mathrm{CHA}_{2} \mathrm{DS}_{2} \text {-VASc score, } \\
\text { median (IOR) }\end{array}$ & $1(2)$ & $1(2)$ & 0.569 \\
\hline $\begin{array}{l}\text { Time elapsed since AF } \\
\text { diagnosis (months), } \\
\text { median (IQR) }\end{array}$ & $28(13)$ & $36(33)$ & 0.463 \\
\hline Persistent AF (n, \%) & $5(8.6 \%)$ & $2(22.2 \%)$ & 0.235 \\
\hline
\end{tabular}

The P-wave duration and dispersion, $0 \mathrm{~T}$ duration and dispersion, $\mathrm{Tp}-\mathrm{Te}$ duration, and $\mathrm{Tp}-\mathrm{Te} / \mathrm{QT}$ ratio were observed to increase significantly after CB-A. There were no significant correlations between basal $\mathrm{P}$-wave dispersion and age $(r=-0.005$; $p=0.97), B M I(r=-0.12 ; p=0.35)$, the time since the diagnosis of AF $(r=0.23 ; p=0.07)$, or the LA diameter $(r=0.05 ; p=0.71)$.

AF recurrence was observed in $9(13.4 \%)$ patients during follow-up. The mean follow-up duration was $29.1 \pm 15.5$ months. Among patients with recurrence, 3 were observed to experience early recurrence, and 5 were observed to experience late recurrence. The demographic characteristics, cardiovascular risk profiles, and echocardiographic parameters of patients with and without AF recurrence are displayed in Table 3. Patients with $\mathrm{AF}$ recurrence had a significantly higher $\mathrm{LA}$ diameter and lower left ventricular (LV) ejection fraction values than patients who were free of recurrence. There were no significant differ-

\begin{tabular}{|lcccc|}
\hline $\begin{array}{l}\text { Table 4. Results of binary logistic regression analysis for evaluating } \\
\text { potential independent predictors of atrial fibrillation recurrence }\end{array}$ \\
\hline \multicolumn{4}{c}{$\begin{array}{c}\text { 95\% confidence } \\
\text { interval }\end{array}$} \\
\cline { 2 - 4 } & Odds ratio & Lower & Upper & P value \\
\hline Left atrial diameter & 6.83 & 0.78 & 59.61 & 0.082 \\
Ejection fraction & 0.93 & 0.84 & 1.03 & 0.152 \\
Delta heart rate & 0.99 & 0.98 & 1.01 & 0.486 \\
Delta P disp & 1.04 & 0.93 & 1.15 & 0.497 \\
Delta QTc disp & 1.07 & 0.95 & 1.19 & 0.267 \\
Delta V5 Tp-Te & 0.93 & 0.85 & 1.01 & 0.087 \\
\hline P disp - P wave dispersion, QTc disp - corrected QT dispersion \\
\hline
\end{tabular}

ences between the groups in terms of age, sex, BMI, frequency of hypertension, frequency of diabetes mellitus, frequency of obesity, and frequency of LV hypertrophy (Table 3). The time from the first diagnosis of $A F$ and the frequency of persistent $A F$ were also similar in patients with AF recurrence compared with patients who were free of recurrence.

The results of the binary logistic regression analysis constructed for the potential predictors of AF recurrence are displayed in Table 4. None of the parameters studied were independent predictors of the AF recurrence after CB-A.

The intraobserver intraclass correlation coefficients (ICCs) for $\mathrm{P}$ dispersion, QTc dispersion, and the Tp-Te duration were $0.73,0.65$, and 0.74 , respectively; and the interobserver ICCs were $0.68,0.76$, and 0.70 , respectively.

\section{Discussion}

The principal finding of this study was that electrocardiographic parameters that had been assumed to reflect inhomogeneous atrial conduction and ventricular repolarization heterogeneity increased significantly in the acute phase after CB-A. However, the magnitude of alteration in each ECG parameter failed to predict AF recurrence.

Previous studies have evaluated the changes in electrocardiographic P-wave parameters after AF ablation and their association with recurrence (12-14). P-wave dispersion has been considered a noninvasive electrocardiographic marker for atrial remodeling and a predictor of $A F(9,13)$. The OTc interval has also been suggested to be associated with the development of $A F$, and a prolonged or a shortened $\mathrm{QT}$ interval has been reported to constitute a risk for the development of $\operatorname{AF}(15,16)$. However, there are limited data in the literature regarding the effect of AF ablation on the OT interval. QTc prolongation has been reported to be an independent risk factor for arrhythmia recurrence in patients with hypertrophic cardiomyopathy undergoing AF ablation (17). To the best of our knowledge, our study was the first to examine the effect of PVI on electrocardiographic $\mathrm{P}$ dispersion, $\mathrm{OT}$ interval, and $\mathrm{OT}$ dispersion.

Increased P-wave duration and dispersion have been known to reflect prolongation of intra-atrial and interatrial conduction 
times and inhomogeneous atrial propagation of sinus impulses (18). These electrophysiological alterations create a suitable milieu for the development of atrial arrhythmias and AF (18). $\mathrm{P}$-wave dispersion has been used as a marker of reverse atrial remodeling after AF ablation in previous studies (13). Fujimoto et al. (13) have reported decreased $P$ dispersion values at 3 and 6 months after AF ablation in patients who remained free of AF after an ablation procedure. However, $\mathrm{P}$ dispersion did not change 1 day or 1 month after the procedure. Furniss et al. (12) have reported reduced $\mathrm{P}$-wave dispersion early after AF ablation, and the reduction was most significant in patients who had undergone hybrid ablation via staged surgical and catheter ablation with more extensive substrate modification. In the only study that evaluated the changes in $\mathrm{P}$-wave parameters after CB-A, Kizilirmak et al. (14) have found significant decreases in $\mathrm{P}$-wave amplitude, duration, and dispersion values 12 hours after the procedure. The authors reported that there were no significant differences between patients with and without recurrence in regard to $\Delta \mathrm{P}$ wave duration and $\Delta \mathrm{P}$ dispersion; however, a decreased $P$ amplitude was shown to be a predictor of a good clinical outcome following CB-A. We found significantly increased $\mathrm{P}$-wave duration and dispersion after CB-A in our study. Our findings regarding the effect of AF ablation on P-wave parameters are in disagreement with those of the abovementioned studies. We measured ECG parameters immediately after CB-A, and we think that tissue edema related to cryo-injury might be responsible for increased heterogeneity in atrial impulse propagation. The heart rate was observed to significantly increase after CB-A in our study, which may be a sign of autonomic modulation. Hou et al. (19) have investigated the interactions between the extrinsic and intrinsic cardiac autonomic nervous system in modulating electrophysiological properties and AF initiation in an animal model. The authors have showed that anterior right ganglionated plexi (GP) ablation attenuated effective refractory period (ERP) shortening and AF inducibility with right vagosympathetic trunk stimulation; however, superior left GP ablation did not affect AF inducibility with left vagosympathetic trunk stimulation, although it eliminated ERP shortening. Hou et al. (19) have suggested that the anterior right GP might serve as an integration center for both right and left vagosympathetic trunks for modulation of sinus rate. Previous studies have reported that GP modification led to higher maintenance rates of sinus rhythm. The increased heart rates noted after CB-A in our study might be the result of an inadvertent effect of cryoablation on the right anterior GP. If this hypothesis is true, then it may be suggested that the increased heart rate post ablation might be associated with decreased AF inducibility and recurrence. Yorgun et al. (11) have showed that recurrence of AF during follow-up was decreased in patients who had undergone $\mathrm{PVI}$ via CB-A and showed vagal reactions during the procedure. The authors have suggested that cardiac autonomic nervous system modification via inadvertent ablation of the GP during antral PVI might have had an additional beneficial effect over PVI on sustaining sinus rhythm in the long term. Guckel et al. (20) have also reported intraprocedural vagal reaction as an independent predictor of AF-free survival after CB-A for persistent AF. Maj et al. (21) have observed an increase in heart rate after CB-A of AF and reported that the increase in heart rate correlated with better outcomes after cryo-PVI possibly owing to cardiac neuromodulation. We also observed a significant increase in heart rate; however, the magnitude of change in the heart rate failed to predict recurrence.

Nguyen et al. (22) have studied the effect of PVI on the QTc interval and observed a significant increase in QTc after AF ablation. The increase in OTc was at a maximum in the immediate postoperative period, and the repolarization parameters returned to baseline after 1 month. The clinical significance of this observation and the impact on postoperative outcomes was discussed as a subject of a further study that has not yet been published (22). Our observation related to the QT duration was similar to that of Nguyen et al. (22). The cause of increases in the QTc interval, QTc dispersion, Tp-Te interval, and Tp-Te/QT ratio in our study is not clear; however, we believe that autonomic modulation might also play a role in the increases in these parameters. Inadvertent GP modulation during CB-A might also have led to an imbalance between the sympathetic and parasympathetic innervations of the ventricle. In an experimental animal study, $\mathrm{He}$ et al. (23) have reported that GP ablation prolonged the ventricular effective refractory period (ERP) and action potential duration but did not increase their spatial dispersion in normal hearts. GP ablation increased the risk of ventricular arrhythmias in hearts after acute myocardial ischemia in that study. However, vagal inhibition with atropine led to QT shortening in normal subjects. Aksu et al. (24) have evaluated the effects of cardioneuroablation with parasympathetic GP ablation on the QT interval and heart rate. They reported that QTc did not change significantly within 24 hours; however, it was shortened significantly in the long-term follow-up. The cause of these discrepant observations is not clear. We think that autonomic modulation of the heart is a complex process and that modulation of the GP via CB-A does not directly result in sympathetic dominance with parasympathetic withdrawal. Autonomic remodeling that might have occurred as a result of $A F$ progression might also be involved in the genesis of CB-A-induced QTc prolongation and the increases in the OTC disp and Tp-Te values.

Only the LA diameter and left ventricular ejection fraction were found to be significantly different in patients with AF recurrence than in patients without recurrence. Only 3 patients had recurrence within 3 months after CB-A. The low number of these patients with early recurrence precluded analysis of the effect of early recurrence on late recurrence. The time since first AF diagnosis and the ratio of persistent AF cases in the recurrent group were higher than in patients without recurrence; however, the difference failed to reach statistical significance. We believe that the failure to reach statistical significance might be related to the low number of patients in the recurrent AF group.

We think that our study may have important clinical implications. We observed a significant and consistent increase in all electrocardiographic parameters studied in the acute phase after CB-A. This observation points to the significant inadvertent 
effect of CB-A on the myocardium and cardiac ANS in addition to the intended PVI. The magnitudes of the changes in those ECG parameters may serve as noninvasive markers to evaluate inadvertent effects of CB-A. We had a very low number of patients with recurrence, which might have interfered with the statistical analysis. The results of our study might provide an impetus for future large-scale studies to evaluate the value of CB-A-induced alterations in electrocardiographic parameters for predicting recurrence of $A F$.

\section{Study limitations}

The inherent limitations of a study with a retrospective design were also valid for our study. We could not obtain information related to the procedural details and cooling characteristics of CB-A for each patient. Our patient population was small with recurrence of $A F$ only in a limited number of patients during the follow-up period. The number of late recurrences in the study population was too low to predict the effect of several variables on recurrence. The course of alterations regarding changes in electrocardiographic parameters in the subacute and chronic phases after CB-A is not clear.

\section{Conclusion}

Electrocardiographic parameters assumed to reflect inhomogeneous atrial conduction and ventricular repolarization heterogeneity increased significantly in the acute phase after CB-A. The results of further prospective studies are required to examine the time-related course of these alterations and their impact on clinical outcomes.

Acknowledgements: Authors would like to thank Metin Okay and Devrim Gürbüz for their contribution to $\mathrm{CB}-\mathrm{A}$ procedures.

Conflict of interest: None declared.

Peer-review: Externally peer-reviewed.

Author contributions: Concept - A.U., A.Küp, A.Kepez; Design A.U., A.Küp, A.Kepez; Supervision - A.U., A.Küp, A.Kepez; Fundings A.U., A.Küp, S.D., K.G., B.G.K., M.Ç., G.T., A.Kepez, T.A.; Materials - A.U., A.Küp, S.D., K.G., B.G.K., M.Ç., G.T., A.Kepez, T.A.; Data collection \&/or processing - A.U., A.Küp, S.D., K.G., B.G.K., M.Ç., G.T., A.Kepez, T.A.; Analysis \&/or interpretation - A.U., A.Küp, A.Kepez; Literature search A.U., A.Küp, A.Kepez; Writing - A.U., A.Küp, A.Kepez; Critical review A.U., A.Küp, A.Kepez, T.A.

\section{References}

1. Kirchhof P, Benussi S, Kotecha D, Ahlsson A, Atar D, Casadei B, et al.; ESC Scientific Document Group. 2016 ESC Guidelines for the management of atrial fibrillation developed in collaboration with EACTS. Eur Heart J 2016; 37: 2893-962. [Crossref]

2. Calkins H, Hindricks G, Cappato R, Kim YH, Saad EB, Aguinaga L, et al. 2017HRS/EHRA/ECAS/APHRS/SOLAECE expert consensus statement on catheter and surgical ablation of atrial fibrillation: Executive summary. Europace 2018; 20: 157-208. [Crossref]
3. Kuck KH, Brugada J, Fürnkranz A, Metzner A, Ouyang F, Chun KR, et al.; FIRE AND ICE Investigators. Cryoballoon or Radiofrequency Ablation for Paroxysmal Atrial Fibrillation. N Engl J Med 2016; 374: 2235-45. [Crossref]

4. Cheniti G, Vlachos K, Pambrun T, Hooks D, Frontera A, Takigawa M, et al. Atrial Fibrillation Mechanisms and Implications for Catheter Ablation. Front Physiol 2018; 9: 1458. [Crossref]

5. Jayachandran JV, Sih HJ, Winkle W, Zipes DP, Hutchins GD, Olgin $\mathrm{JE}$. Atrial fibrillation produced by prolonged rapid atrial pacing is associated with heterogeneous changes in atrial sympathetic innervation. Circulation 2000; 101: 1185-91. [Crossref]

6. Chang CM, Wu TJ, Zhou S, Doshi RN, Lee MH, Ohara T, et al. Nerve sprouting and sympathetic hyperinnervation in a canine model of atrial fibrillation produced by prolonged right atrial pacing. Circulation 2001; 103: 22-5. [Crossref]

7. Arora R, Ulphani JS, Villuendas R, Ng J, Harvey L, Thordson S, et al. Neural substrate for atrial fibrillation: implications for targeted parasympathetic blockade in the posterior left atrium. Am J Physiol Heart Circ Physiol 2008; 294: H134-44. [Crossref]

8. Gould PA, Yii M, McLean C, Finch S, Marshall T, Lambert GW, et al. Evidence for increased atrial sympathetic innervation in persistent human atrial fibrillation. Pacing Clin Electrophysiol 2006; 29: 821-9. [Crossref]

9. Pérez-Riera AR, de Abreu LC, Barbosa-Barros R, Grindler J, Fernandes-Cardoso A, Baranchuk A. P- wave dispersion: an update. Indian Pacing Electrophysiol J 2016; 16: 126-33. [Crossref]

10. Castro-Torres $Y$, Carmona-Puerta R, Katholi RE. Ventricular repolarization markers for predicting malignant arrhythmias in clinical practice. World J Clin Cases 2015; 3: 705-20. [Crossref]

11. Yorgun H, Aytemir K, Canpolat U, Şahiner L, Kaya EB, Oto A. Additional benefit of cryoballoon-based atrial fibrillation ablation beyond pulmonary vein isolation: modification of ganglionated plexi. Europace 2014; 16: 645-51. [Crossref]

12. Furniss G0, Panagopoulos D, Kanoun S, Davies EJ, Tomlinson DR, Haywood GA. The Effect of Atrial Fibrillation Ablation Techniques on P Wave Duration and P Wave Dispersion. Heart Lung Circ 2019; 28: 389-96. [Crossref]

13. Fujimoto Y, Yodogawa K, Takahashi K, Tsuboi I, Hayashi H, Uetake $\mathrm{S}$, et al. Noninvasive evaluation of reverse atrial remodeling after catheter ablation of atrial fibrillation by $\mathrm{P}$ wave dispersion. Heart Vessels 2017; 32: 1375-81. [Crossref]

14. Kizilirmak F, Demir GG, Gokdeniz T, Gunes HM, Cakal B, Guler E, et al. Changes in Electrocardiographic PWave Parameters after Cryoballoon Ablation and Their Association with Atrial Fibrillation Recurrence. Ann Noninvasive Electrocardiol 2016; 21: 580-7. [Crossref]

15. Mandyam MC, Soliman EZ, Alonso A, Dewland TA, Heckbert SR, Vittinghoff $E$, et al. The $\mathrm{OT}$ interval and risk of incident atrial fibrillation. Heart Rhythm 2013; 10: 1562-8. [Crossref]

16. Nielsen JB, Graff C, Pietersen A, Lind B, Struijk JJ, Olesen MS, et al. J-shaped association between QTc interval duration and the risk of atrial fibrillation: results from the Copenhagen ECG study. J Am Coll Cardiol 2013; 61: 2557-64. [Crossref]

17. Wen SN, Liu N, Li SN, Wu XY, Salim M, Kang JP, et al. OTc Interval Prolongation Predicts Arrhythmia Recurrence After Catheter Ablation of Atrial Fibrillation in Patients With Hypertrophic Cardiomyopathy. Circ J 2015; 79: 1024-30. [Crossref]

18. Aytemir K, Ozer N, Atalar E, Sade E, Aksöyek S, Ovünç K, et al. P wave dispersion on 12-lead electrocardiography in patients with paroxysmal atrial fibrillation. Pacing Clin Electrophysiol 2000; 23: 1109-12.[Crossref] 
19. Hou Y, Scherlag BJ, Lin J, Zhang Y, Lu Z, Truong K, et al. Ganglionated plexi modulate extrinsic cardiac autonomic nerve input: effects on sinus rate, atrioventricular conduction, refractoriness, and inducibility of atrial fibrillation. J Am Coll Cardiol 2007; 50: 61-8. [Crossref]

20. Guckel D, Schmidt A, Gutleben KJ, Körber B, Fischbach T, Horstkotte D, et al. Pulmonary vein isolation and beyond: Predictive value of vagal reactions in second-generation cryoballoon ablation for the outcome of persistent atrial fibrillation. Heart Rhythm 2020; 17: 600-6. [Crossref]

21. Maj R, Borio G, Osório TG, lacopino S, Ströker E, Sieira J, et al. Predictors of cardiac neuromodulation achieved by cryoballoon ablation performed in patients with atrial fibrillation who were in sinus rhythm before the ablation. Int J Cardiol 2020; 310: 86-91. [Crossref]
22. Nguyen D, Hourmozdi J, Sridhar AR, Prutkin J, Robinson M, Akoum $\mathrm{N}$. Transient prolongation of QTc interval post pulmonary vein isolation for atrial fibrillation. J Am Coll Cardiol 2019; 73 (9 Suppl 1): 452. [Crossref]

23. He B, Lu Z, He W, Wu L, Cui B, Hu X, et al. Effects of ganglionated plexi ablation on ventricular electrophysiological properties in normal hearts and after acute myocardial ischemia. Int $\mathrm{J}$ Cardiol 2013; 168: 86-93. [Crossref]

24. Aksu T, Guler TE, Bozyel S, Golcuk SE, Yalin K, Lakkireddy D, et al. Medium-term results of cardioneuroablation for clinical bradyarrhythmias and vasovagal syncope: effects on $\mathrm{QT}$ interval and heart rate. J Interv Card Electrophysiol 2021; 60: 57-68. [Crossref] 